\title{
Pupillometry of taste: Methodological guide - from acquisition to data processing - and toolbox for MATLAB
}

\author{
Anaïs Lemercier 国, a,b,c,d, Geneviève Guillot a, Philippe Courcoux e, Claire Garrel a, Thierry \\ Baccino c,d, Pascal Schlich b \\ a Centre de Recherche Pernod Ricard, France; \\ b INRA, UMR1324 Centre des Sciences du Goût et de l'Alimentation, France; \\ c CHART/LUTIN (EA 4004), Cité des sciences et de l'industrie, France; \\ d Université Paris VIII, France ; \\ e ONIRIS, Unité de Sensométrie et Chimiométrie, Nantes, F-44322, France
}

\begin{abstract}
The food sensory science community has recently shown an increasing interest towards the measurement of emotions induced by product consumption. In this paper, we propose a standard method to objectively and quantitatively explore emotions in tasting situations through measurement and analysis of pupil diameter. Pupillometry is a well-known method for investigating cognitive load and emotional effects. However, since a standard method to analyze pupil response data is lacking, we provide here a guided methodology, from data acquisition to data processing. An example of an application is also provided. The advantages and major drawbacks of this method are discussed.
\end{abstract}

Keywords $\approx$ Pupillometry, tasting, methodology, toolbox for MATLAB

$\equiv$ anais.lemercier@gmx.com

\section{Introduction}

Pupil studies have been used in psychology for many years. In her seminal work, Loewenfeld (1993) provides a history of pupil use in psychology, including research about voluntary pupil movements in the 18th century, "conditioned" and "orienting" reflexes at the beginning of the 20th century, and "attitude," "interest," etc., taken up by Hess in the 1960s. Since the 1960s, various pupillometry studies examined cognitive and emotional stimuli. Researchers have reported that pupil size is correlated to levels of cognitive effort (Hess \& Polt, 1966; Bradshaw, 1968; Ullwer, Ries, Foth, \& van det Meer, 2010), and to emotional load or preferences (Barlow, 1969; Partala \& Surakka, 2003; Bradley, Miccoli, Escrig, \& Lang, 2008; Laeng, 2010). Other types of stimuli or tasks have also been investigated, including memory processing (Laeng, 2010; Sirois \& Jackson, 2010; Wu, Laeng, \& Magnussen, 2010) and violation of expectations in infants (Gredebäck, 2010; Hepach \& Westermann, 2010). Pupils also dilate consecutively to stimuli causing emotion such as fear, pain, and shock, as well as stress and fatigue (Wilhelm \& Wilhelm, 2010). The bulk of empirical work suggests that pupil diameter varies according to cognitive and emotional loads. However, the pupillometry method is recent and a standard method to analyze pupil response data has not yet been developed.

Pupillary diameter is known to vary from 1.7-2.2 $\mathrm{mm}$ in myosis (constriction of the pupil), to $7.5-8 \mathrm{~mm}$ in mydriasis (dilation of the pupil; Rouvière \& Delmas, 1981; Larmande \& Larmande, 1989). For several decades now, sophisticated pupillometry video equipment, based on infrared technology, has been used to estimate diameters to the hundredth of a millimeter (Lowenstein \& Loewenfeld, 1958; Loewenfeld \& Rosskothen, 1974), and current systems have a resolution better than $0.025 \mathrm{~mm}$ in diameter on individual measurements, at rates of $60 \mathrm{~Hz}$ and even up to $240 \mathrm{~Hz}$ (Granholm \& Steinhauer, 2004).

Over time, many different studies have used different number of participants ( $\mathrm{n}$ ) and different ways to pre-process (smoothing, blink replacement and baseline) and process (time window, dependent variable, statistical tests and graphical representation) pupil response data (Table 1). However, due to the lack of any standardization, particularly for data preprocessing, comparisons between data are not always 
possible and meta-analyses are not advisable.

The sensory community has recently shown increased interest towards the measurement of emotions induced by product consumption or usage. Since emotions affect food preferences and choices, this community has an interest in evaluating emotions related to products. Until now, emotions have been mainly measured by questionnaires or assessment scales such as the EsSense Profile ${ }^{\mathrm{TM}}$ of King, Meiselman, and Carr (2010). This questionnaire consists of 39 feeling items for a subject to rate from "Not at all" (1) to "Extremely" (5). Other questionnaires have been used for perfumes or, more widely, for odors (Chrea et al., 2009; Porcherot, 2010; 2012; Ng, Chaya, \& Hort, 2013). This type of questionnaire, especially when used for food products, must be adapted to each product and must provide a subjective measurement of emotions, which may lead to additional large between- and within-subject variations.

Since human pupil size is directly affected by emotional stimuli, pupil size changes due to product responses could be used as an objective and unbiased (it is involuntary) measure of emotions provoked by tasting a product. However, although human pupil size is directly affected by emotional stimuli, almost no data exists about the effect of olfactory, gustatory and trigeminal stimuli on pupil dilation or constriction. To our knowledge, only two papers about this type of stimuli have been published. Hess and Polt (1966) showed that changes in pupil size could be a measure of taste difference. More than 40 years later, Schneider and colleagues (2009) showed that changes in pupil diameter indicated differences between the modalities and the strength of odor stimuli, but were not related to the hedonic value of odors.

Through this paper, we aim to propose a standard method to objectively and quantitatively explore emotions in tasting situations through the measurement of pupil dilation. The hypothesis is that when humans feel emotions while tasting a product, their pupils will dilate. We thus provide a procedure of data acquisition, data pre-processing, and data processing, and then conclude with an example of an application. We have also attached three MATLAB routines to this paper that we used to help us carry out these analyses.

\section{Data Acquisition}

\section{Participants}

In previous work, the number of participants in pupillometry studies has greatly varied. A sample of 20 references (Table 1 at the end of the article) revealed a minimum of ten, a maximum of 45 , an average of 24 , and a median of 21 participants. Based on this observation, samples of 20 to 24 participants seemed to be optimal for effect sizes associated with pupil diameter. Moreover, based on our mean observations, to obtain a test power of $90 \%$ with $\alpha=0.05$, an average sample size of 23 participants would be required for detecting significant pupil dilation of approximately $0.09 \mathrm{~mm}$, corresponding to a percentage change of $2.4 \%$. To conclude, a minimum of 23 participants is recommended.

\section{Experimental setup}

We used a Tobii T60 eye tracker (60 Hz sampling rate) for our purposes. This device is designed for tracking eye movements as well as assessing pupil diameter. We propose guidelines for conducting a pupillometry study, some of which are specific to the product tasting situation when using an on-screen eye tracker. First, it is necessary to control the brightness to avoid bias due to the light. For this, we recommend using an artificial light as uniformly as possible in the testing room, and to keep it constant between participants. Second, the participant's movements (head, arms) must be controlled. In fact, movements can disrupt the signal (disturbance of IR beams) or provoke dilation or contraction if the room is not uniformly lighted. Consequently, the subject must consume the product without any head movement. For example, when working with a liquid product, the container must be filled almost to the top, allowing the subject to take a sip without moving his or her head. Use of a straw could further help when it is appropriate.

\section{Task, Stimulus Material and Procedure}

Task.

The task can be divided into three periods for each stimulation.

Rest period. The rest period consists of measuring the pupil diameter while the subject is not receiving any stimulus. This measurement serves as the baseline.

Measurement period: The measurement period consists of measuring the specific reaction of the pupil to a

The Quantitative Methods for Psychology 
stimulus, or the natural pupil variation if there is no stimulus.

Rinsing period: The rinsing period is a rest period for the subject's eyes, during which the subject has only to rinse his or her mouth with water without watching the screen.

\section{Stimulus material \& room test.}

To determine the best room lighting conditions and the display to be used, we conducted an experiment to test these two factors (light and screen), each with two modalities (ceiling light (100-lux)-spotlight (50-lux) and gray screen $\left(30 \mathrm{~cd} / \mathrm{m}^{2}\right)$-black screen $\left(0.30 \mathrm{~cd} / \mathrm{m}^{2}\right)$, respectively). ${ }^{1}$ Illuminance for both light conditions was measured at the approximate position of the participant's eyes when facing the monitor. Results showed a percentage of missing values that were higher for the black screen $(M=12.6, S D=2.3)$ than for the gray screen $(M=4.6, S D=1.0)\left[F(1,160)=10.63, p=0.001, y^{2}\right.$ $=0.04]$, and higher for the spotlight $(\mathrm{M}=11.9, \mathrm{SD}=2.3)$ than for ceiling light $(\mathrm{M}=6.1, \mathrm{SD}=1.1)[\mathrm{F}(1,160)=7.20$, $\left.\mathrm{p}=0.008, \mathrm{y}^{2}=0.03\right]$. A significant interaction between light and screen $\left[F(1,160)=3.89, p=0.050, \mathrm{y}^{2}=0.02\right]$ showed that for the light effect depending on the screen, the percentage of missing values is lower for ceiling light with the black screen alone, whereas the percentage of missing values is equivalent for both light conditions with a gray screen. In conclusion, the best conditions among those tested were ceiling light (100lux) and a gray screen $\left(30 \mathrm{~cd} / \mathrm{m}^{2}\right)$. It is recommended that the experimenter carry out a similar pilot test in order to validate his/her experimental conditions.

Displays are presented for each period using Tobii Studio experimental control software. The displays differ depending on the period. For the rest and measurement periods of the main test, the displays have to be identical and neutral. We recommend using a gray screen on which a black cross appears to facilitate the subject's concentration on the screen. A

115 participants were recruited for this experiment. Each participant realized three trials in each condition. Each trial consisted of three phases. Firstly, a gray or black fixation cross appeared respectively on the black or gray screen for $2 \mathrm{~s}$ to adapt the participant to the experimental conditions, the subject was not receiving any stimulus. Then, the subject took a sip of water while the same fixation cross appeared for $3 \mathrm{~s}$. Then, participants had $20 \mathrm{~s}$ to rest before the next trial starts. The percentage of missing values was collected during the second phase. gray screen was preferable to a black screen because of the results reported above. The cross displayed on the screen must be fixed to avoid the influence of gaze position on pupil size measurement (Gagl, Hawelka and Hutzler, 2011). The display for the rinsing period is clear since no measurement is made during this period. However, it is also recommended to use a gray screen to avoid an excessive change of luminance. We recommend limiting the rest periods to $1 \mathrm{~s}$ and the measurement periods to $3 \mathrm{~s}$. A model of a Tobii Studio project is available on the journal's web site to this paper (Pupillometry Test_example.nas).

\section{Procedure.}

The subject sits on a chair in such a way that his or her face is $60 \mathrm{~cm}$ from the screen. The procedure is conducted in four steps:

1. Explanation of the test session and statement of instructions by the experimenter

We recommend that the experimenter give the instructions to the subject orally rather than having the subject read them on the screen. The instructions have to be identical for all subjects.

\section{Calibration of the eye tracker}

The calibration phase, for which the apparatus provides a specific procedure, aims to adapt parameters of the eye gaze and pupil estimation algorithms to the idiosyncratic properties of each participant's eyes. The calibration has to be carried out at the beginning of each session. If it does not work, the data cannot be recorded and the participant has to be excluded.

\section{Trial runs}

The third step consists of running several training trials to verify that the subject understands the instructions.

\section{Measurement(s)}

The experimenter notes each time the subject takes a mouthful or a sip of the product in order to capture the initial time of the stimulus exposure.

\section{Participant pre-selection.}

The participants can be pre-selected before the experiment begins, keeping certain conditions in mind. Some people cannot participate in a pupillometry test because of their pupil size (either too large or too small), because they have strabismus, have had laser surgery, etc. To establish the pre-selection method, we determined what an unusual percentage of missing values is on the basis of our last observations of 25 


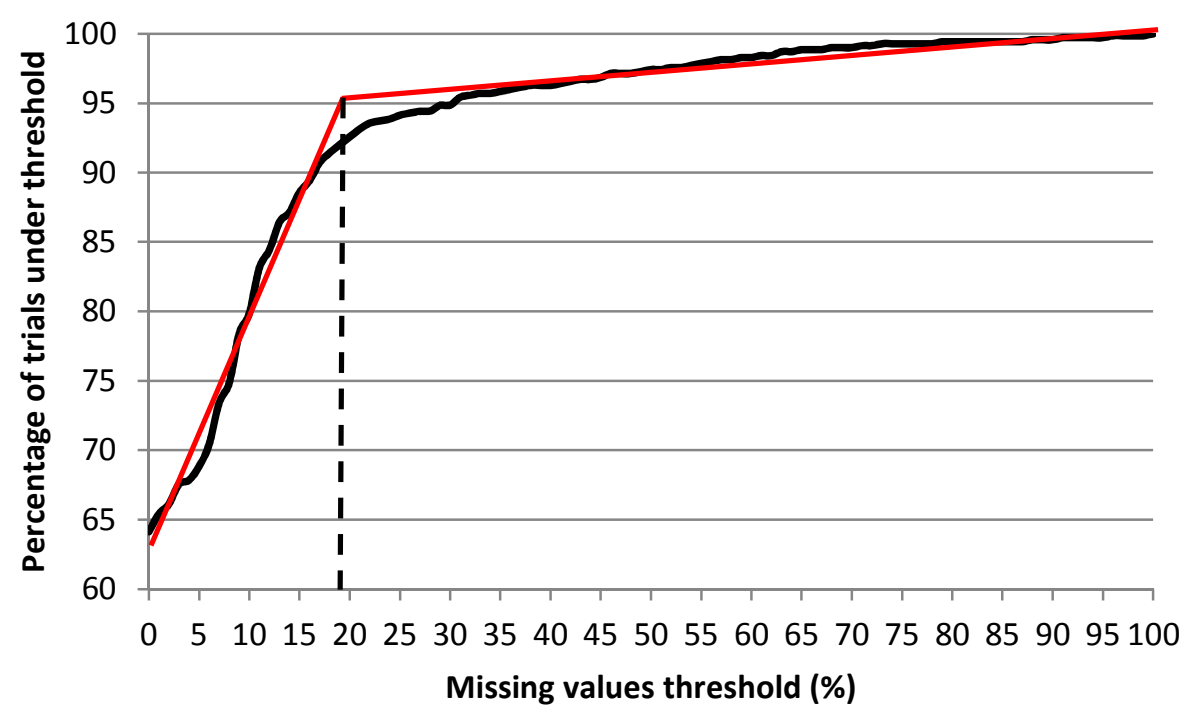

Figure 1 - Percentage of trials under successive fixed thresholds of missing values from 0 to $100 \%$

participants, with light optimized conditions (ceiling light (100-lux) and a gray screen $\left.\left(30 \mathrm{~cd} / \mathrm{m}^{2}\right)\right)$. Twentyeight trials were done per participant (25 participants * 28 trials $=700$ trials). First, the average percentage of missing values was calculated per trial, with an average over trials of approximately $5.90 \%(\mathrm{SD}=0.50)$. The percentage of trials under successive fixed thresholds of missing values from 0 to $100 \%$ was then observed (by the calculation step by step of the percentage of trials with less than $1 \%, 2 \%, 3 \%$, until $100 \%$ of missing values ) (Figure. 1). An inflection point observed at $18 \%$ seems to transcribe the border between the usual (standard) and the unusual percentage of missing values with more than $91 \%$ of trials with less than $18 \%$ of missing values. Based on these observations, we chose to fix a threshold of $18 \%$ of missing values beyond which the value could be considered as unusual. Experimenters could choose to use the same threshold or to determine it by carrying out a similar pilot test in order to determine the usual percentage of missing values in their fixed experimental conditions. For the pre-selection, each participant's pupil diameter has to be measured during a short test. The percentage of missing values is then calculated. We recommend not selecting participants with a higher percentage of missing values than the fixed threshold. A MATLAB routine, available on the journal's web site, is proposed to identify the percentage of missing values in the data in order to help make the decision (DataPreSelect.m).

\section{Data Pre-processing}

\section{Data Extraction}

From the raw data, which is a continuous stream of pupil size estimates, the size of which being a function of sampling rate and task duration, specific pupil responses need to be retrieved for each stimulus. The variables of interest are time, left and right pupil sizes, and event. Depending on the device, a validity index of each measurement or equivalent could also be retrieved (these reflect the estimated validity of individual samples). Given that the latency of pupillary reaction is 200-250 milliseconds (Rougier \& Riss, 2000) and, on the basis of our observations, the ending time of a specific reaction is one to two seconds, we recommend observing the results over a period of 2.5 seconds from stimulus onset. Finally, data are retrieved as well for up to one second before stimulus onset, for baseline correction (explained later).

\section{Cleaning Data}

Regardless of the eye tracking device used, gaze-loss samples are unavoidable (i.e., from eye blinks). Depending on the device, each missing value is arbitrarily recorded as a default value or deleted by the experimental control software, and then estimated by regression or interpolation. However, too many missing values could affect the signal quality. We recommend keeping only recordings with less than $18 \%$ of missing 

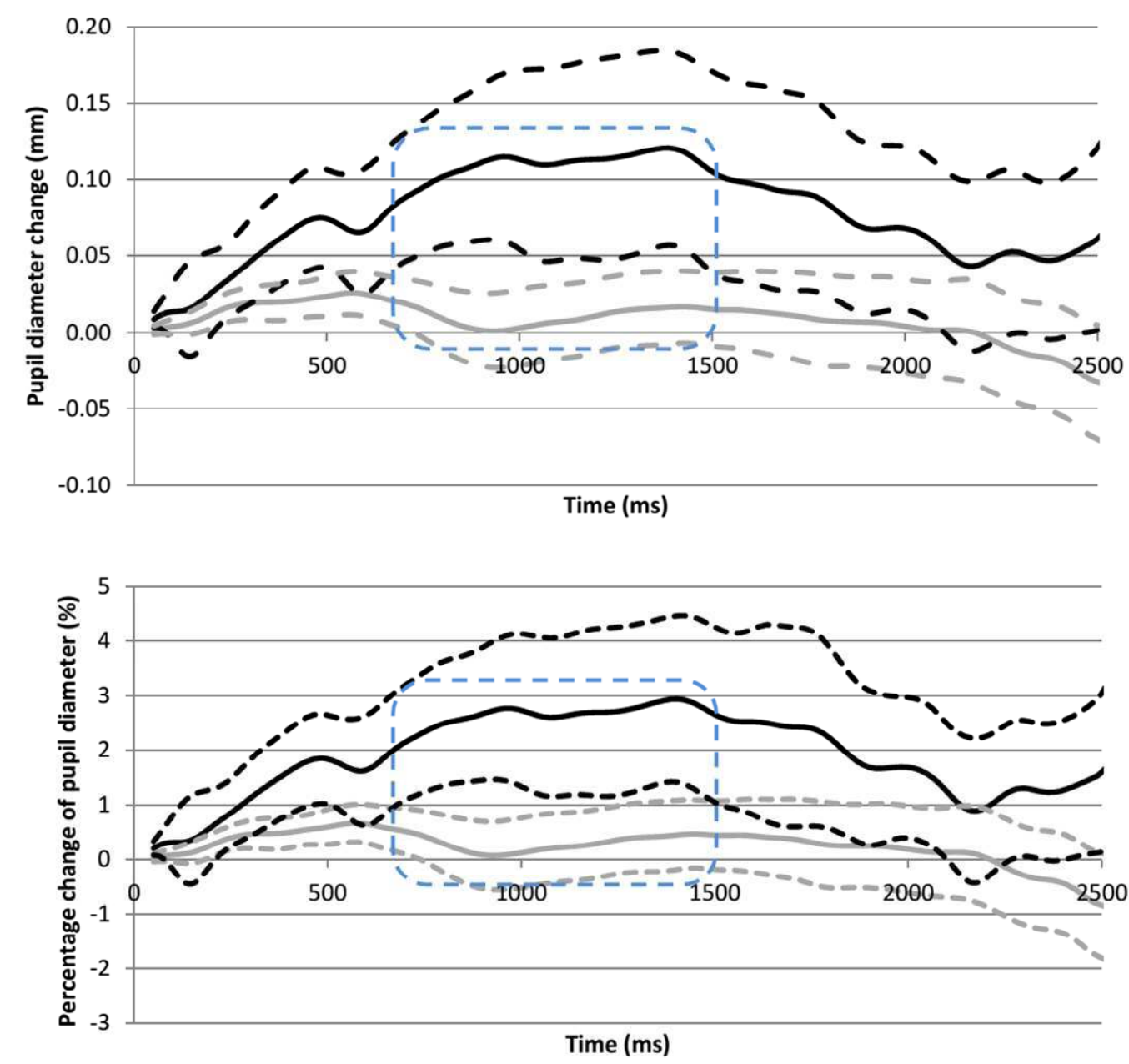

Clean palette

-- Confidence interval for clean palette $(90 \%)$

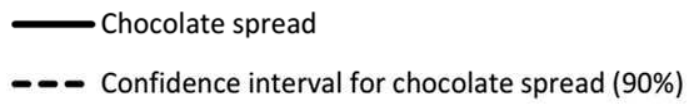

_ $-{ }_{-}$Significant period of difference between the two signals

Figure 2 - Mean pupillary responses after ingestion of spread and during clean palette

values to ensure reliable results, as already suggested for participant pre-selection.

According to Jackson and Sirois (2009), missing values from breaks should first be estimated before running analyses. If a missing value occurs on one eye only, the sample could be estimated by the value of the other eye since there is a high correlation $(>9$ ) between left and right pupil diameters. Otherwise, a linear interpolation could be drawn from the average of the last three values before and the first three values after the break in samples. Jackson and Sirois (2009) developed a MATLAB function to interpolate missing samples, which we have available on the journal's web site (DataCleanLR.m). This function first filters the data to prevent an increase in variability using a low-pass digital filter. We chose a 10-point average filter (166.67 $\mathrm{ms}$ ) to be near the average of our observations, based on values found in the literature (average $=169.59 \mathrm{~ms}$ Table 1). Data are then interpolated. Finally, pupil data from both eyes at each sample time are averaged. This data cleaning is carried out on data as of $1 \mathrm{~s}$ before the stimulus and up to $2.5 \mathrm{~s}$ after the stimulus.

\section{Baseline Correction}

To allow the elimination of inter-subject variability in terms of pupil size, as well as the elimination of a residue of previous pupillary reaction, data were corrected by removing a baseline from each data point. 


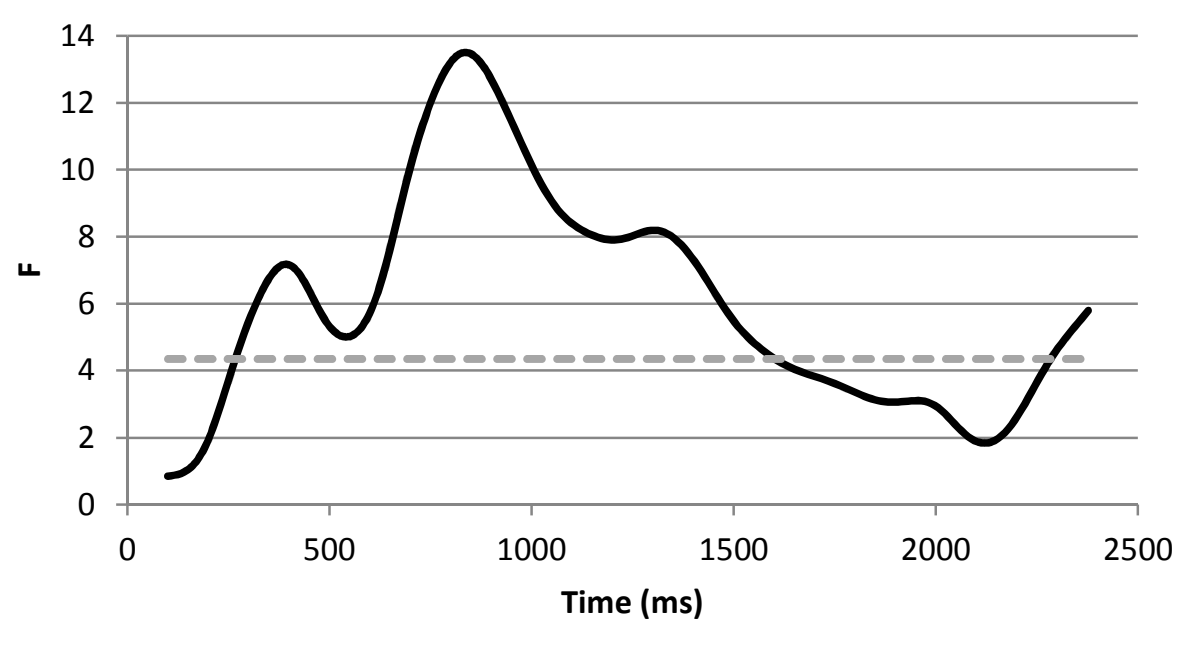

$$
\text { Condition effect } \quad-\quad-\text { Significance threshold }(\alpha=5 \%)
$$

Figure $3 \approx \mathrm{F}$ value for condition variable over time

The baseline was defined as the average pupil size of the interval from $-200 \mathrm{~ms}$ to $0 \mathrm{~ms}$ to stream onset, in keeping with values commonly found in the literature (Kuchinke et al., 2007; Võ et al., 2008; Borneman et al., 2010; Raisig et al., 2010; Kuchinke et al., 2011; Prehn et al., 2011; Wierda et al., 2012). This reference value represents the pupil size at time $t_{0}$. The results could be expressed in two ways: (i) baseline-corrected pupil diameter in $\mathrm{mm}$ using the following equation: $X_{\text {change }}=X_{\text {data }}$ - baseline; and (ii) percentage change of pupil diameter using the following equation:

$$
\%_{\text {change }}=\frac{X_{d a t a}-\text { baseline }}{\text { baseline }} \times 100 \text {. }
$$

We recommend expressing the results of both of these formulas to make it possible to compare data with those from previous studies. However, in the case of statistical tests, it is recommended to use only the percentage change of pupil diameter, which allows for the elimination of additional inter-individual variability.

A MATLAB routine for selecting, cleaning, and correcting data is available on the journal's web site (DataPreprocess.m) (for more details, see the document referred to as "\#Readme", attached to the routine).

\section{Data Processing}

All of the data processing methods presented below have one of the following two objectives: (i) comparing a product to a control situation in order to know if there is a significant dilation of the pupil; (ii) comparing two or more products in order to know if there is a difference between them in terms of pupil dilation.

\section{Curve}

The curve method of analysis can respond to the two objectives, and consists of representing pupil diameter evolution over time. A confidence interval (CI) can be added to the curves to make them more informative, highlighting periods when there seems to be a significant difference. We used a $90 \%$ CI. It is less rigorous than the usual value of $95 \%$, and may be justified by the variability in the measurement of pupil response. These CIs are used for a first visual interpretation. Two pupil responses to stimuli are considered to be equivalent when the CI curves overlap. Conversely, when the two CI curves do not overlap, the two responses are different, and the direction of this difference can be seen on the plot. If a large number of stimuli are plotted on the same graph, it is not recommended to draw CI boundaries; a complementary method, described later, will clarify the significance of differences from one time to the next.

\section{Peak Dilation}

The peak dilation method can be used to compare two or more products. Peak dilation is computed as the maximum percentage of pupil diameter change. This peak dilation is submitted to a two-way ANOVA with stimulus and subject as factors. 


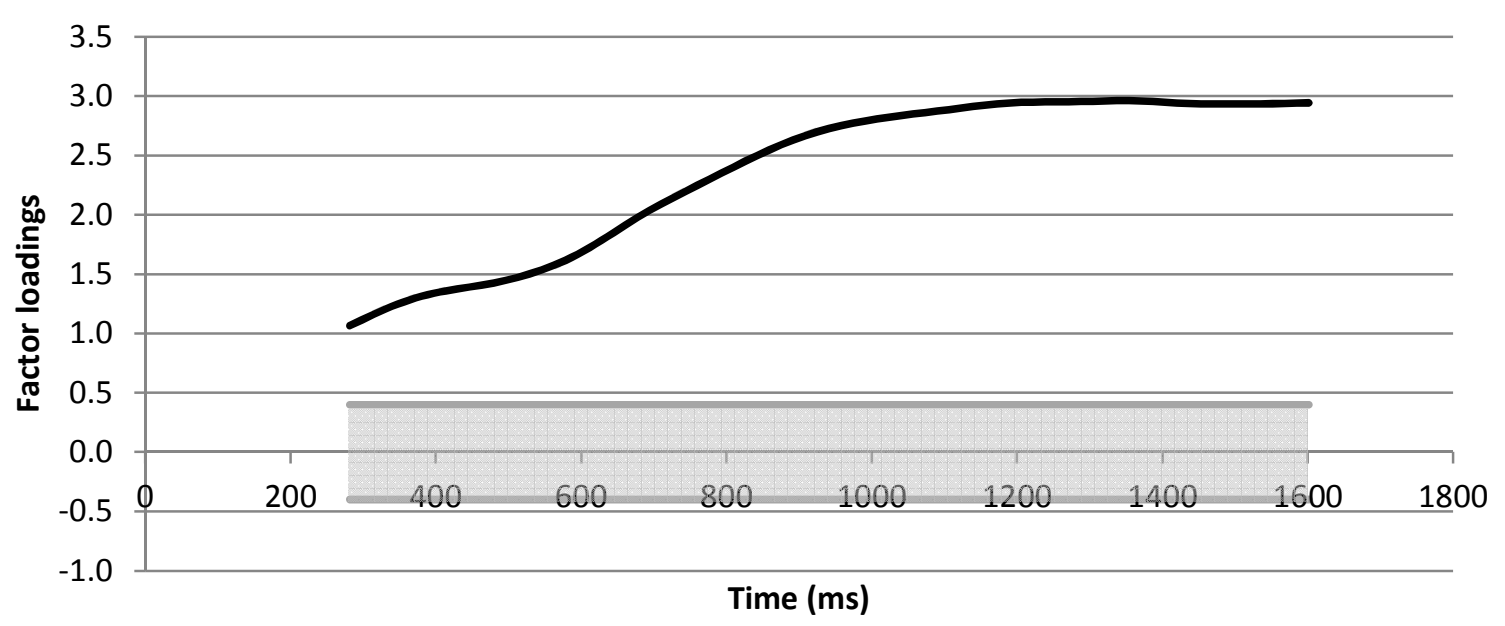

Figure 4 - Factor loadings of the first component identified by PCA analysis ( $91.33 \%$ of the overall variance) - Horizontal lines at -0.4 and 0.4 indicate the border of factor loadings, which are considered to be "meaningful"

\section{Comparison of stimuli by Mobile Average over time}

This consists of comparing the mean pupil diameter in successive time windows. Moving averages over 200 $\mathrm{ms}$ of the percentage change from the baseline are computed. These averages are compared between stimuli by performing a two-way ANOVA with stimulus and subject as factors. To visualize the differences between stimuli, the statistic $\mathrm{F}$ of the stimulus factor is plotted over time. A significance threshold is added to the curve, corresponding to a significance level of 0.05.

\section{Principal Component Analysis}

This last method consists of carrying out a covariance Principal Component Analysis (PCA) where subjects' exposures to a stimulus are the observations, and percentage changes of pupil diameter over significant times are the variables (see Schlens, 2005, for a brief introduction). In order to determine the number of components to be retained to obtain a sufficiently accurate summary of the information in the initial data, the elbow criterion is used. The elbow criterion is based on the observation of an eigenvalue plot observation of a sharp decrease of the function's slope. Factor loadings of the retained components are then plotted. Like Kuchinke et al. (2007), only factor loadings with an absolute value greater than 0.4 will be considered for interpretation. The interpretation consists in identifying parameters that transcribe components (e.g., mean pupil diameter over time). The defined parameters are then calculated, and correlations between components and parameters are observed to validate the interpretation. Finally, a twoway ANOVA with stimulus and subject as factors on the coordinates of each component is computed.

The curve, peak dilation, comparison over time, and PCA methods can be undertaken using MATLAB routines that are also available on the journal's web site (DataProcess.m,

Results_Curves.m, Results_PeakDilation, Results_TimesComparison and Results_PCA) (for more details, see the document referred to as "\#Readme", attached to the routine).

\section{Example of Application}

\section{Material and Method}

Data acquisition, data pre-processing and data processing were realized by following the guidelines previously enunciated.

Data collected from twenty-two participants were used for analysis: 15 men and seven women, with a mean age of 45 years $(S D=2.9)$. They were financially compensated for their participation. All of them had a normal or corrected-to-normal vision and were at least occasional consumers of the product tested.

The product tested was a chocolate spread.

\section{Results}

Curves. The average baseline-corrected pupil diameter and percentage change of pupil diameter evolutions over time for the chocolate spread and the control situation (clean palette) are represented on Figure 2 
with confidence intervals of $90 \%$. The curves of the evolution of the pupil showed pupil dilation for the chocolate spread with a larger pupil diameter than during the natural variations of the pupil diameter from $300 \mathrm{~ms}$ to $1600 \mathrm{~ms}$. The pupil dilation for the chocolate spread was approximately $0.12 \mathrm{~mm}$, corresponding to a variation of $3 \%$ of the pupil diameter at rest.

Comparison over time. We compared moving averages (200 ms) between the spread and the control by performing a two-way ANOVA with stimuli and subjects as factors. The $\mathrm{F}$ statistic of the stimulus factor is plotted over time on Figure 3. The product signal was significantly different from the natural variations of pupil diameter, ranging from $280 \mathrm{~ms}$ to $1600 \mathrm{~ms}$.

PCA. Computing a covariance PCA where subject $x$ condition (chocolate spread or clean palette) are the observations and where the pupil diameter for the significant times $(280 \mathrm{~ms}-1600 \mathrm{~ms})$ are the variables, we identified one principal component (PC) to retain according to the elbow criterion. This PC accounted for $91.33 \%$ of the overall variance. A plot of the factor loadings is illustrated in Figure 4. The retained component represents the average signal. We chose the parameter of the average over time to transcribe this component. The calculation of correlations between PC and the average pupil diameter over time showed significant correlation, $R=0.999(p<0.001)$, confirming our interpretation. Finally, we computed a two-way ANOVA of this component with condition and subject as factors. The ANOVA showed a significant main effect of condition $(p<0.01)$. In contrast, the component was not affected by the subject variable $(p=$ $0.53)$. This result means that the clean palette and chocolate spread do not lead to identical mean pupil diameters.

\section{Conclusion of the test}

The results showed significant pupil dilation for the chocolate spread compared to the natural variations of pupil diameter with the clean palette. The pupil dilation with the chocolate spread was approximately $0.12 \mathrm{~mm}$, corresponding to a variation of $3 \%$ of the pupil diameter at rest. This result was further supported by means of a principal component analysis. This suggests that the chocolate spread provoked emotions for the subjects and that the pupils reflected these emotions. However, the measurement of emotions caused by a food product on the basis of pupil diameter has not been studied in great detail as of this time. Applications on others food products are necessary to ensure that it is a measure of emotions and not just of arousal.

\section{Conclusions}

The methodology guide presented in this paper was developed with the aim of helping anyone interested in conducting a pupillometry test in a tasting situation. The method described here covers data acquisition to data processing. It is obviously not the only way to conduct a pupillometry test and can be improved or adapted.

Pupillometry tests in tasting situations allow researchers to measure pupil response to products, but within certain limits. First, the tasting conditions presented are not natural. Tasting is done in a test room, and the subject must concentrate on a screen while limiting his or her movements. To make the conditions more natural, a head-mounted or other type of wearable eye tracker could be used. The subject would be freer to move. However, this would make it necessary to deal with light variations and to constantly make measurements with a light meter to eliminate pupil variations due to the light (pupil light reflex) (Watson \& Yellott, 2012). Another limit is that emotions cannot be qualified with pupillometry alone. To qualify these emotions, a questionnaire could be administered in which the subject could rate certain emotions. For example, an existing emotions questionnaire could be used, but it would have to be short and simple since it would have to be repeated for each test. The only thing that we can be sure of in pupil response is that we measure arousal (Partala et al., 2003; Bradley, 2008). Also, to have more consistent results, the measurement of pupil size could be coupled with another physiological measure (such as electrodermal activity or heart rate). To correlate other quantitative data with pupil data, the coordinates of the PCA components, which reflect pupil response, could be used.

In terms of material, to limit the subject's movement, the researcher could consider using a chin rest or a straw/flexible tube. However, a chin rest is not suitable for tasting, especially for liquid products, and a straw is not adaptable to all food products, for example, solid foods or liquid products like whisky. The objective of the methodology is to be able to adapt it to all food products. Specific solutions cannot be proposed, but the experimenter is free to adapt the procedure to his/her products to facilitate consumption without excessive head movement.

The MATLAB routines available on the journal's web

The Quantitative Methods for Psychology 
site could be improved. For example, the development of an interface could be considered, but this requires time and, often, a change in the software version or operating system could make the interface unusable.

Finally, to take this analysis a step further, other multivariate analyses could be tested, including Independent Component Analysis, as suggested by Jainta \& Baccino (2010, see Langlois, Chartier, and Gosselin, 2010, for an introduction), or Discriminant Analysis, and more precisely, Partial Least SquaresDiscriminant Analysis (PLS-DA; Barker \& Rayens, 2003).

In conclusion, in this paper, we aimed to demonstrate that pupil dilation that could transcribe emotions can be assessed during a tasting situation, but within certain limits. Among those limits are the lack of terms to interpret the measured emotions that require coupling pupil data with a qualitative questionnaire, the non-natural conditions of tasting, and, finally, the difficulty of controlling the other sources of variations in pupil diameter (stress, fatigue, lighting, etc.). Ultimately, concerning the assessment of emotions during a tasting situation, it would be interesting to apply this method to several other studies with different types of food stimuli. Moreover, it is important to observe that recent results suggest that the pupil size is related to arousal measures (Partala, 2033; Bradley, 2008). Therefore, an examination of this measurement cannot be used to draw definitive conclusions regarding differences in valence judgments.

\section{Authors' notes and acknowledgments}

The authors wish to thank Sylvain Sirois and Iain Jackson for making their MATLAB routines available to us, Sylvain Sirois for his precious help in proof-reading of this paper and Gail Wagman for her precious help in revising the English.

\section{References}

Barker, M., \& Rayens, W. (2003). Partial least squares for discrimination. Journal of Chemometrics, 17(3), 166-173. doi:10.1002/cem.785

Barlow, J. D. (1969). Pupillary size as an index of preference in political candidates. Perceptual and Motor Skills, 28, 587-590.

Bayer, M., Sommer, W., \& Schacht, A. (2011). Emotional words impact the mind but not the body: Evidence from pupillary responses. Psychophysiology, 48(11), 1553-61. doi:10.1111/j.1469-8986.2011. 01219.x
Beatty, J. \& Lucero-Wagoner, B., (2000). The Pupillary System. In: J. T. Cacioppo, L. G. Tassinary, \& G. G. Berntson (Eds.). Handbook of Psychophysiology (2nd ed.) (pp. 142-162). New York: Cambridge University Press.

Bernhardt, P. C., Dabbs, J. M., \& Riad, J. K. (1996). Pupillometry system for use in social psychology. Behavior Research Methods, Instruments, \& Computers, 28(1), 61-66. doi:10.3758/BF03203637

Bernick, N., Kling, A., \& Borowitz, G. (1971). Physiologic Differentiation of Sexual Arousal and Anxiety. Psychosomatic medicine, 33(4), 341-52.

Bitsios, P., Szabadi, E., \& Bradshaw, C. (2004). The fearinhibited light reflex: Importance of the anticipation of an aversive event. International Journal of Psychophysiology: Official Journal of the International Organization of Psychophysiology, 52(1), 87-95. doi:10.1016/j.ijpsycho.2003.12.006

Bornemann, B., Foth, M., Horn, J., Ries, J., Warmuth, E., Wartenburger, I., \& Meer, E. (2010). Mathematical cognition: Individual differences in resource allocation. Zdm Mathematics Education, 42(6), 555567. doi:10.1007/s11858-010-0253-x

Bradley, M., Miccoli, L., Escrig, M., \& Lang, P. (2008). The pupil as a measure of emotional arousal and autonomic activation. Psychophysiology, 45(4), 602-607. doi:10.1111/j.1469-8986.2008.00654.x

Bradshaw, J. L. (1968). Pupil size and problem solving. Quarterly Journal of Experimental Psychology, 20(2), 116-122.

Causse, M., Sénard, J.M., Démonet, J. F., \& Pastor, J. (2010). Monitoring cognitive and emotional processes through pupil and cardiac response during dynamic versus logical task. Applied psychophysiology and biofeedback, 35(2), 115-123. doi:10.1007/s10484-009-9115-0

Chrea, C., Grandjean, D., Delplanque, S., Cayeux, I., Le Calvé, B., Aymard, L., . . S Scherer, K. R. (2009). Mapping the semantic space for the subjective experience of emotional responses to odors. Chemical Senses, 34, 49-62. doi:10.1093/ chemse/bjn052

Conway, C. A., Jones, B. C., Debruine, L. M., Little, A. C., \& Sahraie, A. (2008). Transient pupil constrictions to faces are sensitive to orientation and species. Journal of Vision, 8, 1-11. doi:10.1167/8.3.17

Coquin, J., Tafer, N., Mazerolles, M., Pouquet, O., Pfeiff, R., Richebé, P., \& Janvier, G. (2009). Monitorage de la dilatation pupillaire dans l'évaluation d'une tolérance aiguë au rémifentanil en chirurgie 
cardiaque. Annales françaises d'anesthèsie et de rèanimation, 28(11), 930-935. doi:10.1016/ j.annfar.2009.07.073

Dietz, J., Bradley, M. M., Okun, M. S., \& Bowers, D. (2011). Emotion and ocular responses in Parkinson's disease. Neuropsychologia, 49, 324753. doi:10.1016/j.neuropsychologia.2011.07.029

Dufresne, A., Prom Tep, S., Senechal, S., \& Courtemanche, F. (2010). Physiological Measures, Eye Tracking and Task Analysis to Track User Reactions in User Generated Content. Proceedings of Measuring Behavior, (August 24-27), 218-22.

Einhäuser, W., Stout, J., Koch, C., \& Carter, O. (2008). Pupil dilation reflects perceptual selection and predicts subsequent stability in perceptual rivalry. Proceedings of the National Academy of Sciences of the United States of America, 105(5), 1704-9. doi:10.1073/pnas.0707727105

Espeseth, T., van de Pavert, S. H. P., Jynge, S., Sneve, M. H., \& Laeng, B. (2010). The pupil dilates as a function of attentional effort in multiple object tracking. In EyeTrackConf. Uppsala.

Gabay, S., Pertzov, Y., \& Henik, A. (2011). Orienting of attention, pupil size, and the norepinephrine system. Attention, Perception \& Psychophysics, 73(1), 123129. doi:10.3758/s13414-010-0015-4

Gagl, B., Hawelka, S., \& Hutzler, F. (2011). Systematic influence of gaze position on pupil size measurement: Analysis and correction. Behavior Research Methods, 43(4), 1171-81. doi:10.3758/ s13428-011-0109-5

Geangu, E., Hauf, P., Bhardwaj, R., \& Bentz, W. (2011). Infant pupil diameter changes in response to others' positive and negative emotions. PloS One, 6(11), 110. doi:10.1371/journal.pone.0027132

Goldinger, S. D., \& Papesh, M. H. (2012). Pupil Dilation Reflects the Creation and Retrieval of Memories. Current Directions in Psychological Science, 21, 905. doi:10.1177/0963721412436811

Granholm, E., \& Steinhauer, S. R. (2004). Pupillometric measures of cognitive and emotional processes. International Journal of Psychophysiology, 52, 1-6. doi:10.1016/j.ijpsycho.2003.12.001

Gredebäck, G. (2010). Pupil dilation and social cognition in infancy. In EyeTrackConf. Uppsala.

Heitz, R. P., Schrock, J. C., Payne, T. W., \& Engle, R. W. (2008). Effects of incentive on working memory capacity: behavioral and pupillometric data. Psychophysiology, 45, 119-29. doi:10.1111/j.14698986.2007.00605.x
Hepach, R., \& Westermann, G. (2010). Deriving meaning from infants' pupillary responses to emotional stimuli. In EyeTrackConf. Uppsala.

Hess, E. H. (1960). Pupil size as related to interest value of visual stimuli. Science, 132, 349-50.

Hess, E. H. (1975). The role of pupil size in communication. Scientific American, 233(5), 116-9.

Hess, E. H, \& Polt, J. M. (1966). Changes in pupil size as a measure of taste difference. Perceptual and Motor Skills, 23, 451-455.

Höfle, M., Kenntner-Mabiala, R., Pauli, P., \& Alpers, G. (2008). You can see pain in the eye: Pupillometry as an index of pain intensity under different luminance conditions. International journal of psychophysiology: Official journal of the International Organization of Psychophysiology, 7O(3), 171-175. doi:10.1016/j.ijpsycho.2008.06.008

Honma, M., Tanaka, Y., Osada, Y., \& Kuriyama, K. (2012). Perceptual and not physical eye contact elicits pupillary dilation. Biological Psychology, 89, 112-6. doi:10.1016/j.biopsycho.2011.09.015

Hyönä, J., Tommola, J., \& Alaja, A. M. (1995). Pupil dilation as a measure of processing load in simultaneous interpretation and other language tasks. The Quarterly Journal of Experimental Psychology, 48A(3), 598-612.

Iqbal, S. T., Zheng, X. S., \& Bailey, B. P. (2004). Taskevoked pupillary response to mental workload in human-computer interaction. In Conference on Human factors and computing systems - CHI. Vienna, Austria: ACM Press. doi:10.1145/985921.986094

Jackson, I., \& Sirois, S. (2009). Infant cognition: Going full factorial with pupil dilation. Developmental Science, 12(4), 670-679. doi:10.1111/j.14677687.2008.00805.x

Jainta, S., \& Baccino, T. (2010). Analyzing the pupil response due to increased cognitive demand: An independent component analysis study. International Journal of Psychophysiology, 77(1), 17. doi:10.1016/j.ijpsycho.2010.03.008

Johansson, R., Holmqvist, K., Mossberg, F., \& Lindgren, M. (2011). Eye movements and reading comprehension while listening to preferred and non-preferred study music. Psychology of Music, 4O(3), 339-56. doi:10.1177/0305735610387777

King, S. C., Meiselman, H. L., \& Carr, T. B. (2010). Measuring emotions associated with foods in consumer testing. Food Quality and Preference, 21, 1114-16. doi:10.1016/j.foodqual.2010.08.004

The Quantitative Methods for Psychology 
Klingner, J., Kumar, R., \& Hanrahan, P. (2008). Measuring the task-evoked pupillary response with a remote eye tracker. In Eye Tracking Research \& Applications - ETRA. Savannah, Georgia.

Kuchinke, L., Võ, M. L.-H., Hofmann, M., \& Jacobs, A. M. (2007). Pupillary responses during lexical decisions vary with word frequency but not emotional valence. International Journal of Psychophysiology, 65(2), 132-40. doi:10.1016/j.ijpsycho.2007.04.004

Kuchinke, L., Schneider, D., Kotz, S. a, \& Jacobs, A. M. (2011). Spontaneous but not explicit processing of positive sentences impaired in Asperger's syndrome: pupillometric evidence. Neuropsychologia, 49(3), 331-8. doi:10.1016/ j.neuropsychologia.2010.12.026

Kuchinsky, S. E., Dubno, J. R., Humes, L. E., Ahlstrom, J. B., Cute, S. L., \& Eckert, M. A. (2011). Evaluation of pupil size as an indicator of listening effort. Talk presented at the MUSC Hearing Science Interest Group Meeting.

Kuchinsky, S. E., Ahlstrom, J. B., Vaden, K. I., Cute, S. L., Humes, L. E., Dubno, J. R., \& Eckert, M. a. (2013). Pupil size varies with word listening and response selection difficulty in older adults with hearing loss. Psychophysiology, 50(1), 23-34. doi:10.1111/ j.1469-8986.2012.01477.x

Laeng, B., \& Falkenberg, L. (2007). Women's pupillary responses to sexually significant others during the hormonal cycle. Hormones and Behavior, 52(4), 520-530. doi:10.1016/j.yhbeh.2007.07.013

Laeng, B. (2010). Eyes Wide Open - The Pupillometry of Desire. EyeTrackConf. Uppsala.

Larmande, P. \& Larmande, A. (1989). Neuroophtalomologie. Paris: Masson.

Langlois, D., Chartier, S., \& Gosselin, D. (2010) An Introduction to Independent Component Analysis: InfoMax and FastICA algorithms, Tutorials in Quantitative Methods for Psychology, 6, 31-38.

Loewenfeld, I. E., \& Rosskothen, H. D. (1974). Infrared pupil camera: A new method for mass screening and clinical use. Am J Ophthalmol, 78, 304.

Loewenfeld, I. E. (1993). The Pupil: Anatomy, Physiology, and Clinical Applications. Ames: Iowa State University Press. Chapter 13 (pp. 648-78).

Lowenstein O, Loewenfeld I.E. (1958). Electronic pupillography: A new instrument and some clinical applications. Arch Ophthalmol, 59:352, 63.

Ng, M., Chaya, C., \& Hort, J. (2013). Beyond liking: Comparing the measurement of emotional response using EsSense Profile and consumer defined check- all-that-apply methodologies. Food Quality and Preference, 28, 193-205. doi:10.1016/j.foodqual.2012.08.012

Otero, S. C., Weekes, B. S., \& Hutton, S. B. (2011). Pupil size changes during recognition memory. Psychophysiology, 48, 1346-53. doi:10.1111/ j.1469-8986.2011.01217.x

Palinko, O., Kun, A. L., Shyrokov, A., \& Heeman, P. (2010). Estimating cognitive load using remote eye tracking in a driving simulator. Proceedings of the 2010 Symposium on Eye-Tracking Research \& Applications - ETRA'10, 141-144. doi:10.1145/ 1743666.1743701

Partala, T., \& Surakka, V. (2003). Pupil size variation as an indication of affective processing. International Journal of Human-Computer Studies, 59(1-2), 185198. doi:10.1016/S1071-5819(03)00017-X

Piquado, T., Isaacowitz, D., \& Wingfield, A. (2010). Pupillometry as a measure of cognitive effort in younger and older adults. Psychophysiology, 47(3), 560-69. doi:10.1111/j.1469-8986.2009.00947.x. Pupillometry

Porcherot, C., Delplanque, S., Planchais, A., Gaudreau, N., Accolla, R., \& Cayeux, I. (2012). Influence of food odorant names on the verbal measurement of emotions. Food Quality and Preference, 23, 125133. doi:10.1016/j.foodqual.2011.07.006

Porcherot, C., Delplanque, S., Raviot-Derrien, S., Le Calvé, B., Chrea, C., Gaudreau, N., \& Cayeux, I. (2010). How do you feel when you smell this? Optimization of a verbal measurement of odor-elicited emotions. Food Quality and Preference, 21(8), 938-947. doi:10.1016/j.foodqual.2010.03.012

Prehn, K., Heekeren, H. R., \& van der Meer, E. (2011). Influence of affective significance on different levels of processing using pupil dilation in an analogical reasoning task. International Journal of Psychophysiology, 79, 236-43. doi:10.1016/ j.ijpsycho.2010.10.014

Raisig, S., Welke, T., Hagendorf, H., \& van der Meer, E. (2007). Investigating dimensional organization in scripts using the pupillary response. Psychophysiology, 44(6), 864-73. doi:10.1111/ j.1469-8986.2007.00592.x

Raisig, S., Welke, T., Hagendorf, H., \& van der Meer, E. (2010). I spy with my little eye: detection of temporal violations in event sequences and the pupillary response. International Journal of Psychophysiology: Official Journal of the International Organization of Psychophysiology, 
76(1), 1-8. doi:10.1016/j.ijpsycho.2010.01.006

Rieger, G., \& Savin-Williams, R. C. (2012). The eyes have it: Sex and sexual orientation differences in pupil dilation patterns. PloS One, 7(8), 1-10. doi:10.1371/journal.pone.0040256

Rougier, M., \& Riss, I. (2000). Motricité pupillaire. Encyclopédie Médico-chirurgicale, Neurologie.

Rouvière, H., \& Delmas A. (1981). Anatomie humaine descriptive, topographique et fonctionnelle. 11ème éd. Tome 1. Tête et cou. Paris: Masson.

Schneider, C., Ziemssen, T., Schuster, B., Seo, H., Haehner, A., \& Hummel, T. (2009). Pupillary responses to intranasal trigeminal and olfactory stimulation. Journal of Neural Transmission, 116(7), 885-889. doi:10.1007/s00702-009-0244-7

Siegle, G. J., Granholm, E., Ingram, R. E., \& Matt, G. E. (2001). Pupillary and reaction time measures of sustained processing of negative information in depression. Biological Psychiatry, 49, 624-36. Retrieved from http://www.ncbi.nlm.nih.gov/ pubmed/11297720

Siegle, G. J., Steinhauer, S. R., Carter, C. S., Ramel, W., \& Thase, M. E. (2003). Do the seconds turn into hours? relationships between sustained pupil dilation in response to emotional information and selfreported rumination. Cognitive Therapy and Research, 27(3), 365-382.

Sirois, S., \& Jackson, I. (2010). Pupil dilation, goal attribution, and object identity in infants. EyeTrackConf. Uppsala.

Shlens, J. (2005) A Tutorial on Principal Component Analysis. Retrieved from http://www. brainmapping.org/NITP/PNA/Readings/pca.pdf.

Stone, B., Lee, M., Dennis, S., \& Nettelbeck, T. (2003). Pupil Size and Mental Load. 1st Adelaide Mental Life Conference, Adelaide, S.A

Tombs, S., \& Silverman, I. (2004). Pupillometry: A sexual selection approach. Evolution and Human Behavior, 25, 221-228. doi:10.1016/ j.evolhumbehav.2004.05.001

Ullwer, D., Bornemann, B., Ries, J., Horn, J., Foth, M.,
Preusse, F., \& van der Meer, E. (2009). Resource allocation and problem solving strategies during a geometric analogy task in individuals differing in fluid intelligence. Paper for the 2nd Analogy Conference, NBU Press: Sofia

Ullwer, D., Ries, J., Foth, M., \& van det Meer, E. (2010). Resource allocation and learning in individuals differing in cognitive abilities - insights from pupillometry and eye - movement analysis. In EyeTrackConf. Uppsala.

Urry, H. L., van Reekum, C. M., Johnstone, T., \& Davidson, R. J. (2009). Individual differences in some (but not all) medial prefrontal regions reflect cognitive demand while regulating unpleasant emotion. NeuroImage, 47(3), 852-63. doi:10.1016/ j.neuroimage.2009.05.069

Verney, S. P., Granholm, E., \& Dionisio, D. P. (2001). Pupillary responses and processing resources on the visual backward masking task. Psychophysiology, 38, 76-83. Retrieved from http://www.ncbi.nlm. nih.gov/pubmed/11321622

Võ, M., Jacobs, A. M., Kuchinke, L., Hofmann, M., Conrad, M., Schacht, A., \& Hutzler, F. (2008). The coupling of emotion and cognition in the eye: Introducing the pupil old/new effect. Psychophysiology, 45(1), 130140. doi:10.1111/j.1469-8986.2007.00606.x

Watson, A. B., \& Yellott, J. I. (2012). A unified formula for light-adapted pupil size. Journal of Vision, 12(10), 1-16. doi:10.1167/12.10.12.

Wierda, S. M., Rijn, H. Van, Taatgen, N. A., \& Martens, S. (2012). Pupil dilation deconvolution reveals the dynamics of attention at high temporal resolution. doi:10.1073/pnas.1201858109/-/DCSupplemental. www.pnas.org/cgi/doi/10.1073/pnas.1201858109

Wilhelm, H., \& Wilhelm, B. (2010). View onto alertness - objective assessment of central nervous activation level by pupillography.pdf. EyeTrackConf. Uppsala.

Winter, D. A. (1990). Biomechanics and motors control of human movement. New York: Wiley-Interscience.

Wu, E., Laeng, B., \& Magnussen, S. (2010). Through the eyes of the own-race bias. EyeTrackConf. Uppsala.

\section{Appendix: GUIDELINES FOR USING MATLAB ROUTINES}

Three MATLAB routines (some of them adapted from programs and using a function written by Jackson \& Sirois (2009)) are available on the journal's web site. They were written for the data files of the Tobii Studio. For other types of data files, they will probably need to be adapted. They were written with the objective of comparing a product and a control situation or products between themselves. They have to be adapted if there are factors other than subject and product. Nota bene: stimuli = conditions

Note to programmers: These programs can be improved, adapted and/or modified; feel free to rewrite them. 


\title{
DataPreSelect.m
}

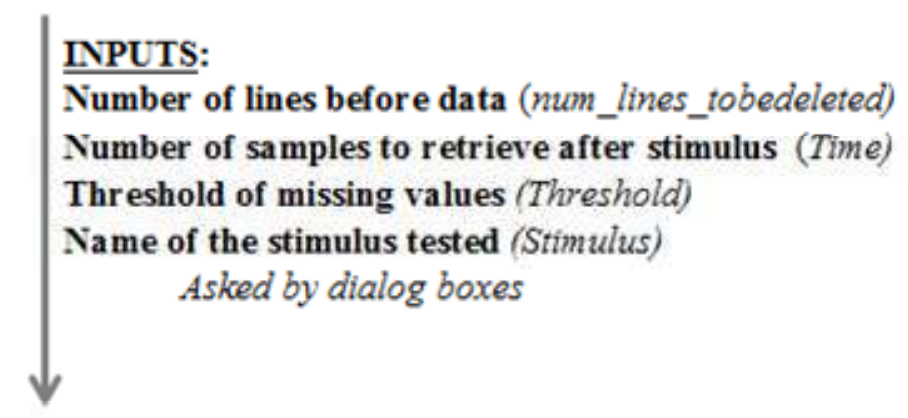

\author{
ANSWER \\ 'This participant can participate in the experiment' \\ Or \\ 'This participant must be exduded from the experiment' \\ AND \\ 'Percentage of missing values $=\ldots$ '..'
}

Figure A.1 DataPreSelect steps

\section{Prerequisite: Test Design}

To be able to retrieve pupil response data specific to a stimulus, a file with a specific name must be added per stimulus as media in the Tobii test (see Tobii Studio Manual). We recommend calling it 'StimulationX' for each stimulation and adding it as an image in jpg format. In fact, the naming convention 'StimulationX.jpg' is the default value in our MATLAB routines (attention: it is the file that must be named 'StimulationX', not the media element). In that way, the variable 'StimuliName' in the raw data will provide information about the stimulation presented at each moment of the recording.

A model of a Tobii Studio project is attached to this paper (PupillometryTest_Example.nas).

\section{MATLAB routine ${ }^{\circ}{ }^{1}$ : DataPreSelect.m}

This program indicates the percentage of missing values for a chosen stimulus in order to help with the decisionmaking during the pre-selection of participants. It is linked to the function 'Data_export_quality'. It must be used for one participant at a time.

Some information must be specified.

Number of lines before data to be deleted: this number varies depending on the variables of the test. To discover it, a file must be opened to see how many lines there are before the first row of data

Number of samples to retrieve after stimulus: this corresponds to the number of samples for which the quality code will be retrieved. It depends on the time of the stimulus tested for the pre-selection. We recommend fixing the time of this stimulus at $2 \mathrm{~s}$ and retrieval at $1.5 \mathrm{~s}$, with 90 samples if the sampling frequency is $60 \mathrm{~Hz}$.

Threshold of missing values: this corresponds to the threshold fixed to decide if the recording is good or not. We recommend $18 \%$ (see 'Subject Pre-selection' in the paper).

Name of the stimulus tested: this corresponds to the name of the file used for the media of the stimulus tested, where the name is indicated as the variable 'StimuliName'.

The program then gives the percentage of missing values observed and the decision: 'This participant can participate in the experiment' or 'This participant must be excluded from the experiment'

A synthesis of the different steps is shown in Figure A.1. 
DataPreprocess.m

\section{INPUTS:}

Number of stimulations (num_stimulations)

Names of stimulations (Stimulations_names)

Number of lines before data (num_lines_tobedeleted)

Asked by dialog boxes

DO YOU WANT TO DE LE TE LOW QUALITY RE CORDINGS?

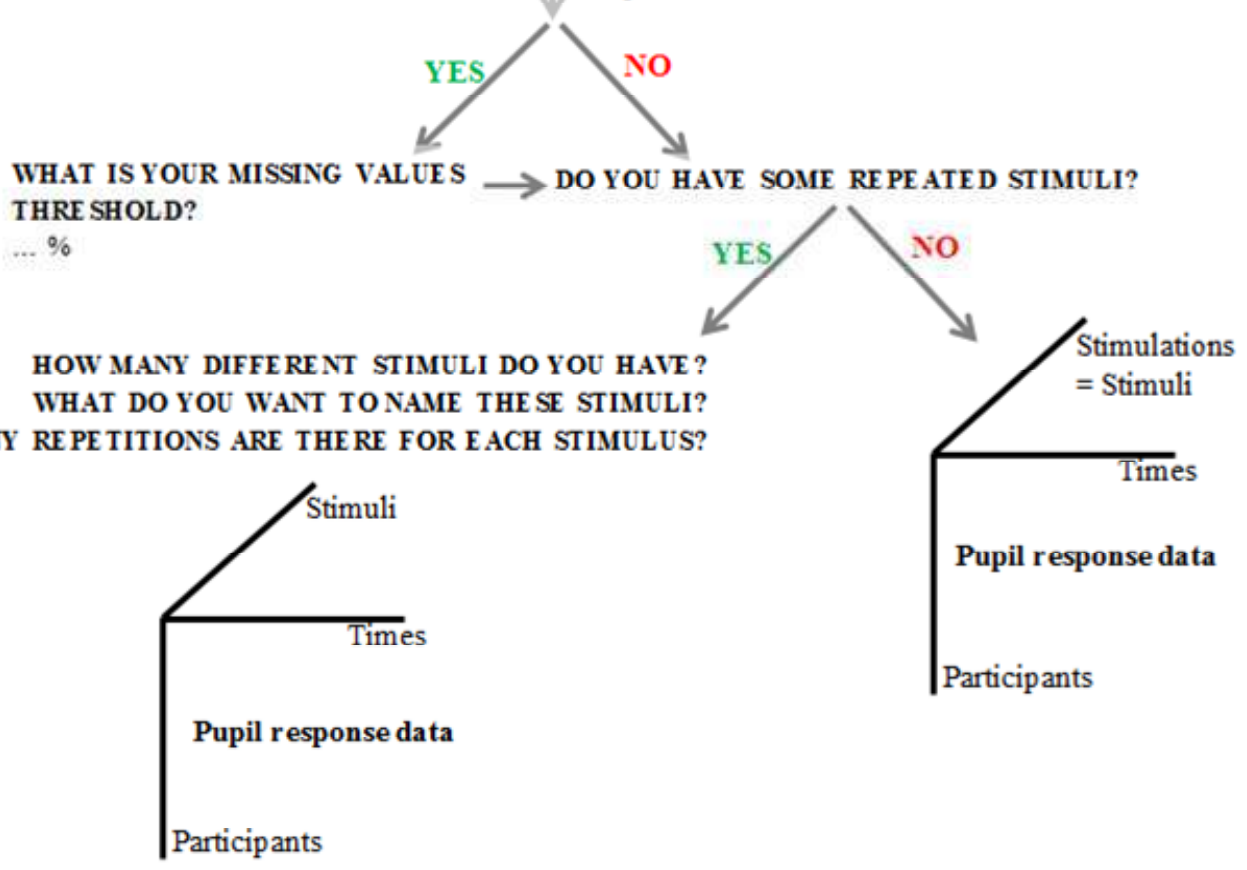

Figure A.2 - DataPreprocess steps

\section{MATLAB routine ${ }^{\circ}{ }^{\circ}$ : DataPreProcess.m}

This program allows the three steps of data pre-processing, extraction, cleaning and baseline correction to be undertaken. It is linked to the functions 'Data_export_data' and 'DataCleanLR' for cleaning. Any use of this last function must recognize and cite the source (Jackson \& Sirois, 2009).

In chronological order, this program:

Selects data as of $1 \mathrm{~s}$ before each stimulus to $2.5 \mathrm{~s}$ after each stimulus (60 and 150 samples, respectively, with a sampling frequency of $60 \mathrm{Hertz}$; it will need to be adjusted for other sampling frequencies)

Cleans data

Corrects data

To execute the program, some information needs to be specified:

Number of stimulations: this corresponds to the number of stimulations in the study where the pupil response is in the raw data file, including repetitions (e.g., if three products are repeated twice each, and one control situation repeated twice, all of which are studied in the same session, ' 8 ' must be indicated).

Names of stimulations: this corresponds to the names of the stimulations presented during the measurement period, 
including repetitions. The default values are 'StimulationX.jpg' in the MATLAB program. Attention: if a stimulus is repeated, all repetitions of this stimulus must be grouped or the program must be modified.

Number of lines before data: as for the MATLAB routine $n^{\circ} 1$, this corresponds to the number of lines to delete before the first data.

A synthesis of the different steps is shown in Figure A.2.

\section{MATLAB routine ${ }^{\circ} 3:$ DataProcess.m}

This program allows pupil data processing on the basis of the four methods proposed in the paper:

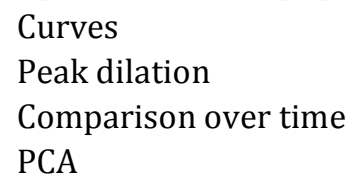

For this, you have to specify what stimuli you want to compare and the rank of these stimuli in the data matrix. Also, some outputs of 'DataPreprocess.m' are necessary: baseline-corrected data and the percentage of change for each stimulation and averages over repetitions for each stimulus. You then have to specify if you want to compare only stimuli (without the control situation). In fact, the peak dilation is computed only when you compare two or more products but not product(s) and a control situation during which there is normally no peak dilation. In some cases, you have to specify yourself, the statistic F of your stimulus factor (you have to read it in Fisher table - In Workspace: numerator $=$ ddf_1 and denominator $=$ ddf_error). To finish, you have to make two decisions. The first one is to determine a significant period over which you want to compute PCA by indicating the beginning of the period and the end. You can do this using the plot of $\mathrm{F}$ (condition factor) over time. The second is the number of components to select by using the elbow criterion while observing the eigenvalue plot. This program does not display the results. To do this, the following programs must be used:

Results_Curves / Resultts_PeakDilation / Results_TimesComparison / Results_PCA

The different steps can be found in Figure A.3.

Note: This program uses the Fisher table. This matrix has to be added to the current folder

\section{MATLAB routines ${ }^{\circ}$ 4-5-6-7: Results_METHOD.m}

These four programs allow you to display the results.

\section{Results_Curves}

This makes it possible to trace the curves of the baseline-corrected pupil diameter and/or the percentage of change of pupil diameter over time. Four questions must be answered:

'Do you want to trace the percentage of change in pupil diameter over time?' (YES or NO)

'Do you want to add confidence intervals?' (YES or NO)

'Do you want to trace the baseline-corrected pupil diameter evolution?' (YES or NO)

'Do you want to add confidence intervals?' (YES or NO)

\section{Results_PeakDilation}

This program indicates if there is a significant condition effect on peak dilations and displays the table of ANOVA results.

\section{Results_TimesComparison}

This program indicates if there is a significant condition effect on the percentage of variation at least once. It also allows you to trace the p-value and/or the statistic $\mathrm{F}$ of the condition effect over time. To do this, you need to answer the following questions:

'Do you want to trace the condition factor p-value over time?' (YES or NO)

'Do you want to trace F of the condition factor over time?' (YES or NO) 


\section{DataProcess.m}

INPUTS (New):

Number of stimuli to compare (num_stimuli)

Ranks of these stimuli in data matrix (Stimuli_ranks)

Statistic $F$ of your stimulus $(F)$

You have to read it in Fisher tabie - he Morkpase: numerator $=$ dat. $l$ and dinominator $=d a]_{-}$etror
INPUTS (From DataPreprocess.m):

Baseline-corrected data and percentages of change for each stimulation and average over repetitions for each stimulus

ARE YOU COMPARING ONLY REAL STIMULI (NOT A CONTROL SITUATION)? (YES OR NO)
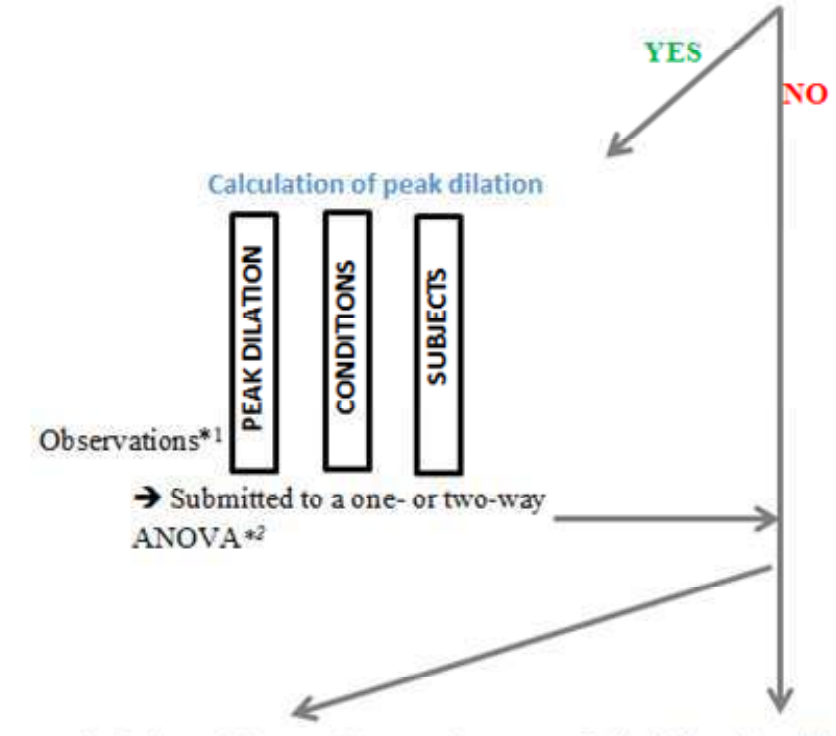

Calculation of the coordinates of

Calculation of mobile averages +

PCA computing on significant curves

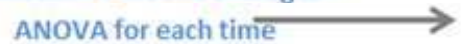
period + ANOVA on each meaningful component

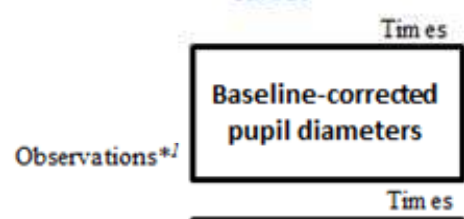

\begin{tabular}{c|c|} 
Observations $^{* 1}$ & $\begin{array}{c}\text { Percentage } \\
\text { changes in pupil } \\
\text { diameters }\end{array}$ \\
\hline
\end{tabular} Observations*

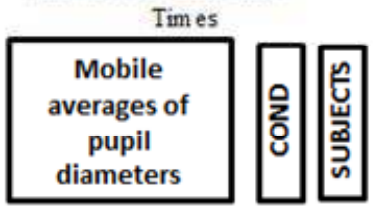

$\rightarrow$ Submitted to a two-way ANOVA*2 Observations*

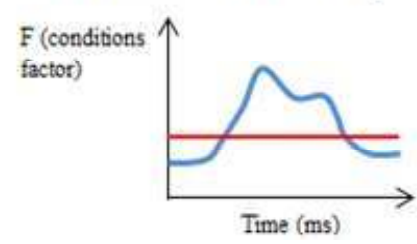

$\rightarrow$ Indication of significant period

*I Observation $=$ condition ${ }^{\text {subject }}$

${ }^{* 2}$ ANOVA with condition and subject as

factors

Figure A.3 $=$ DataProcess steps

\section{Results_PCA}

This last program indicates if there is a meaningful component(s) that discriminate(s) against the conditions and that traces the factor loadings over time to allow the interpretation of the components. 


\section{Citation}

Lemercier, A., Guillot, G., Courcoux, P., Garrel, C., Baccino , P., \& Schlich, P. (2014). Pupillometry of taste: Methodological guide - from acquisition to data processing - and toolbox for MATLAB. The Quantitative Methods for Psychology, 10 (2), 179-195.

Copyright (C) 2014 Lemercier, Guillot, Courcoux, Garrel, Baccino, Schlich. This is an open-access article distributed under the terms of the Creative Commons Attribution License (CC BY). The use, distribution or reproduction in other forums is permitted, provided the original author(s) or licensor are credited and that the original publication in this journal is cited, in accordance with accepted academic practice. No use, distribution or reproduction is permitted which does not comply with these terms.

Received: 15/05/14 Accepted: 16/06/14

Table 1 follows... 

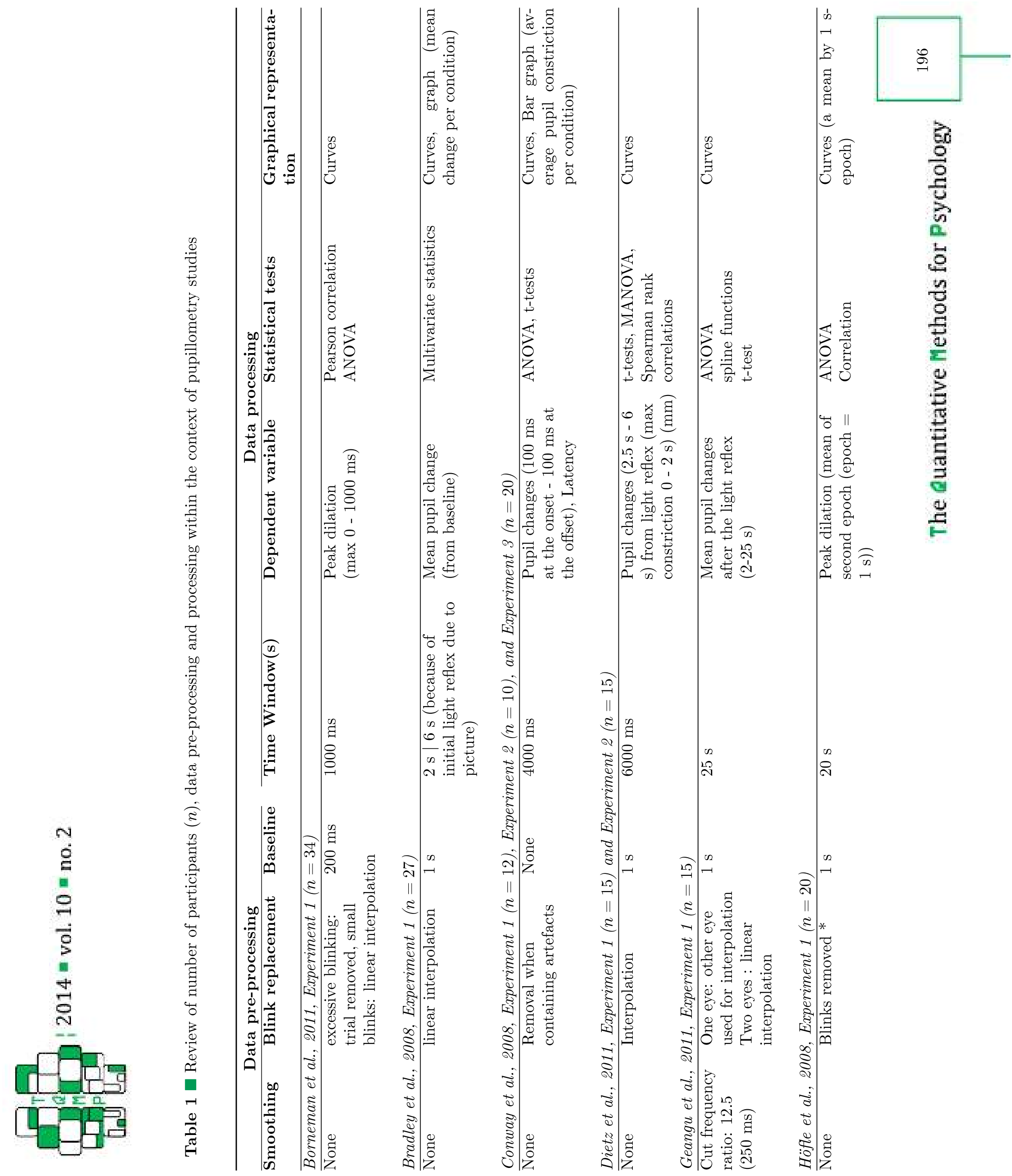

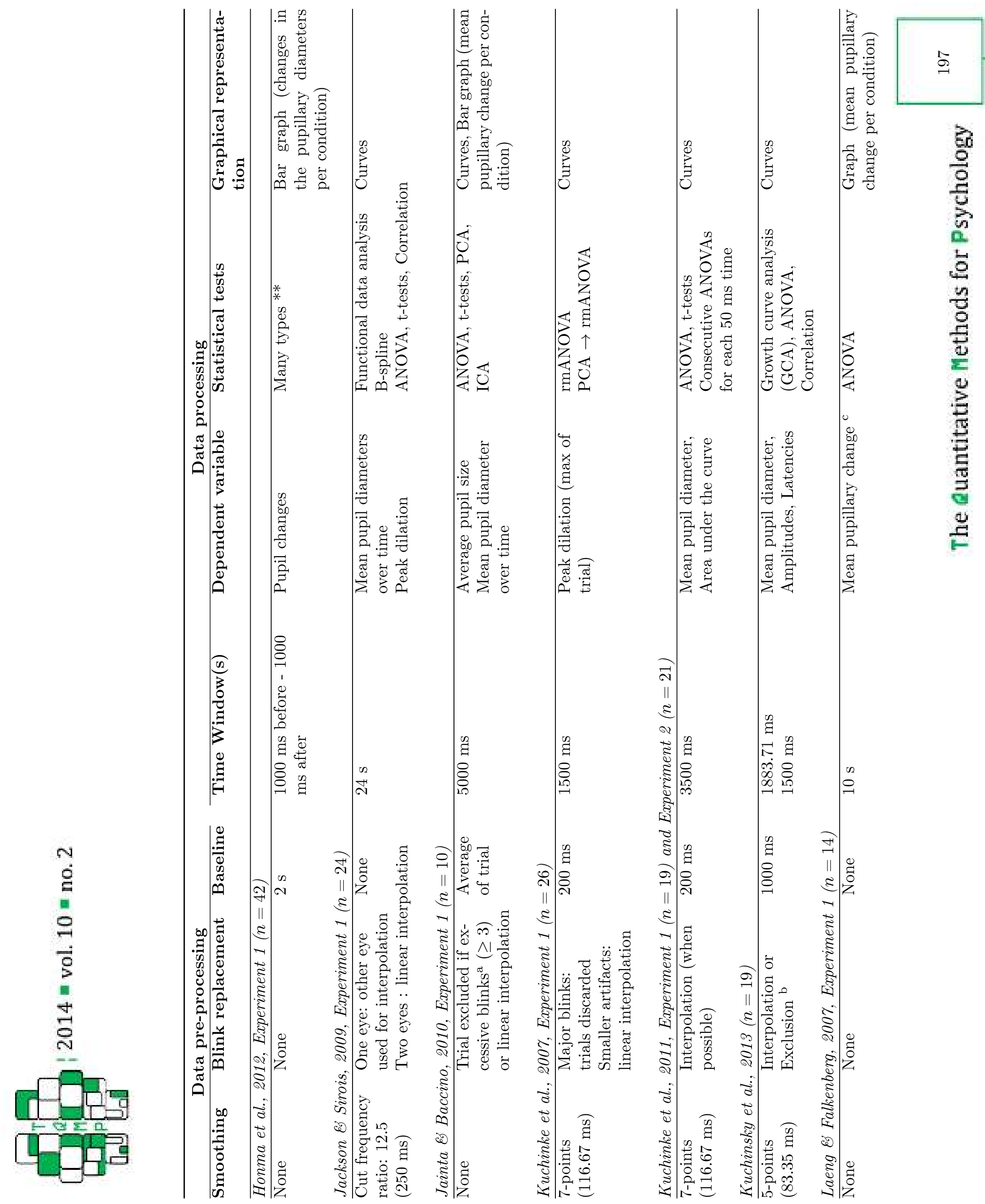

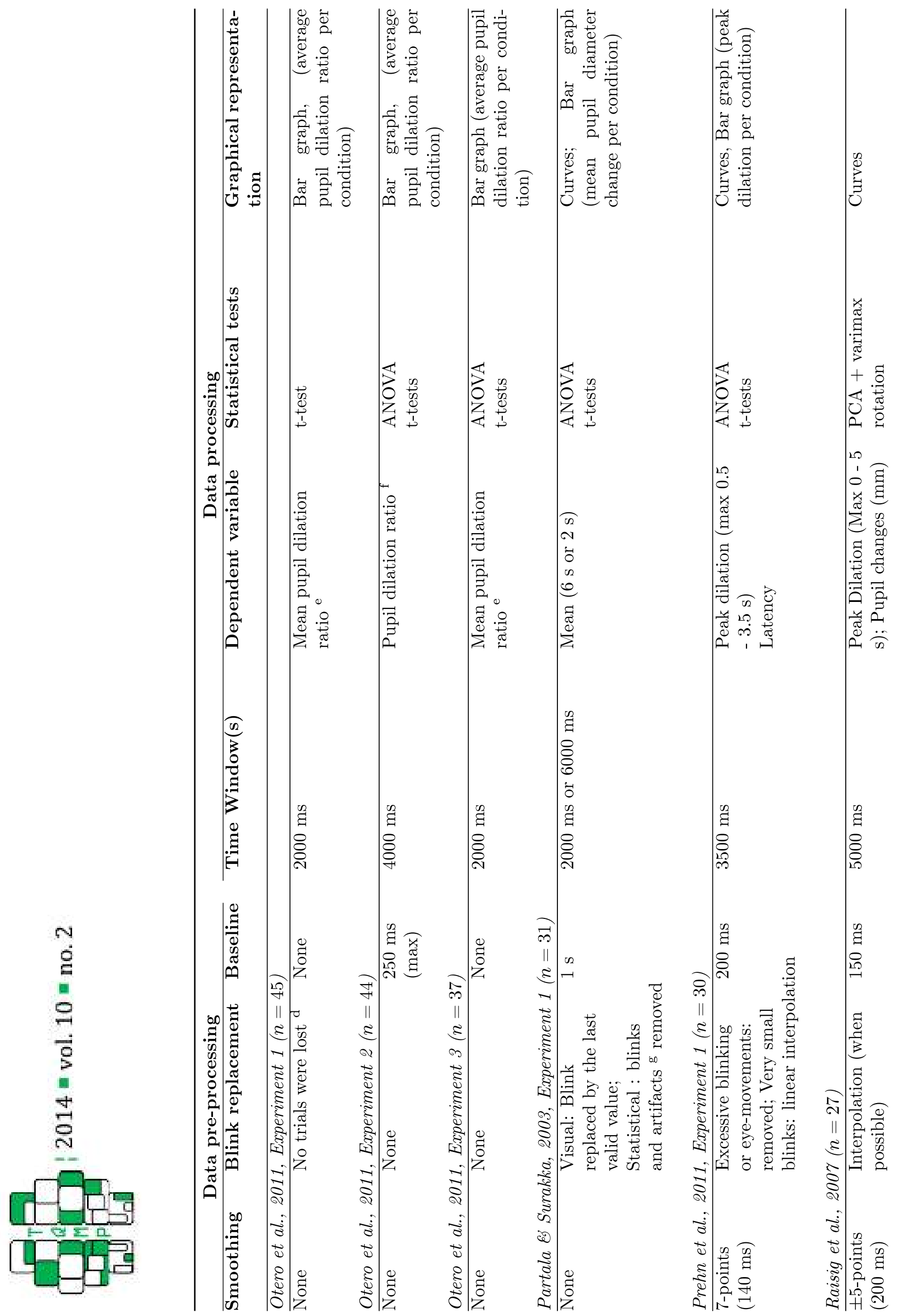

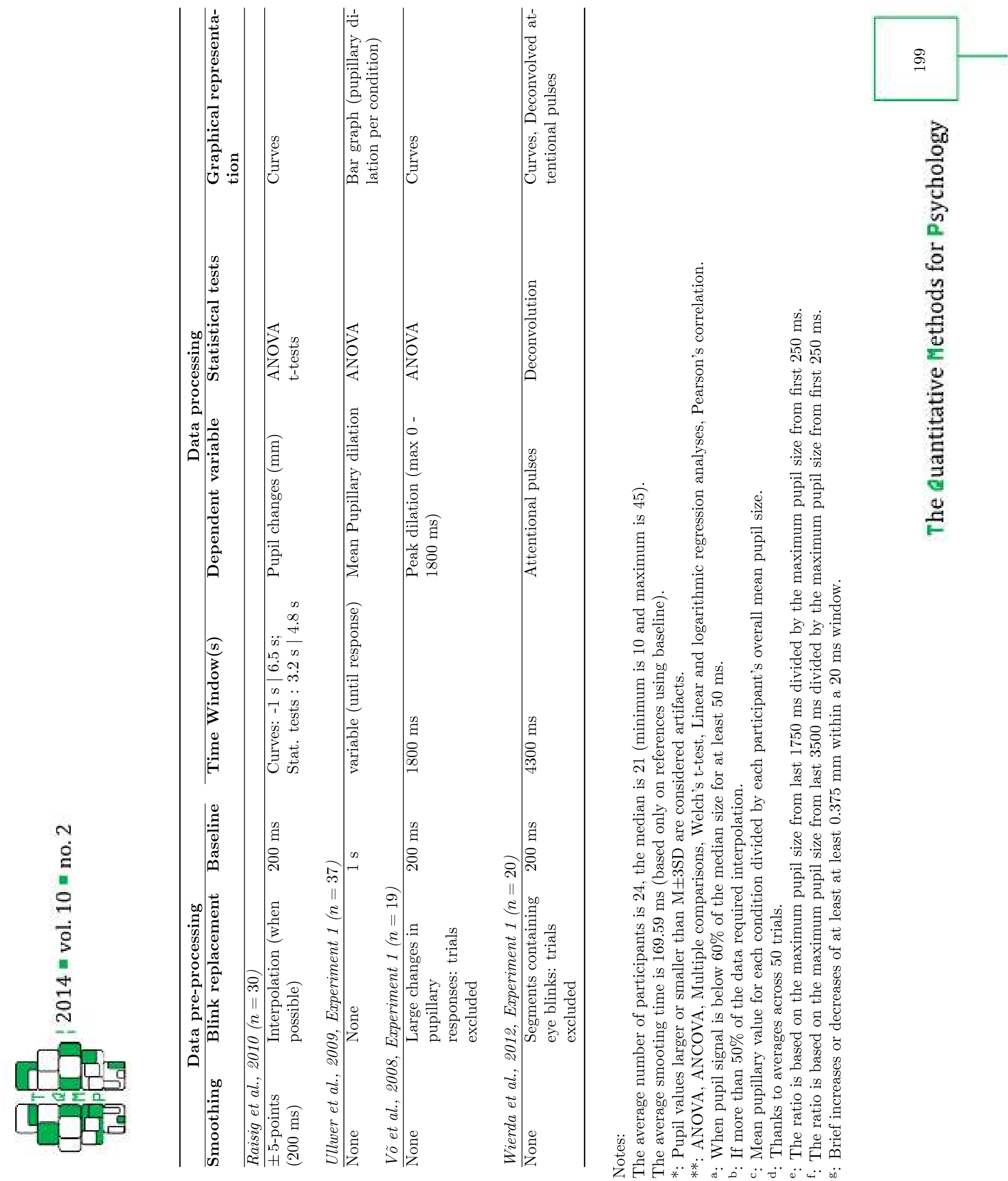